\title{
22
}

\section{Electronic learning contract for the assessment of projects in information systems}

\author{
R.C.W. Kwok and J. Ma \\ Department of Information Systems, City University of Hong \\ Kong \\ Tat Chee Avenue, Kowloon, Hong Kong \\ e-mail: isron@msmail.is.cphk.hk \\ isjian@msmail.is.cphk.hk
}

\begin{abstract}
Assessment of students' learning is a crucial factor that will influence students' approaches to learning. This study investigates the effects of using electronic learning contracts on students' approaches to learning. An Electronic Learning Contract (ELC) is a continuously renegotiable working agreement between students and lecturers for assessing the outcomes of students projects. It focuses on group decision making through electronic meetings towards the learning outcomes. It specifies what students will learn, how this will be accomplished, within what period of time, and what the criteria of assessment will be. A Group Support System (GSS) is used to provide an environment for electronic meeting and to assist the processes for discussing, negotiating, formulating, re-negotiating and revising the content of the ELC among students and lecturers. Students' participation in the construction of the electronic learning contract will enhance their perception of assessment criteria. It will generate the backwash effects of assessment on learning, and thus encourage deep and achieving approaches to learning.
\end{abstract}

\section{Keywords}

Higher education, assessment, learning contract, group support system

\section{INTRODUCTION}

Students' approaches to learning can be classified into surface, deep and achieving approaches (Biggs, 1989; Biggs, 1991; Biggs, 1992). Recent studies (Biggs, 1992; Biggs, 1996) conducted in several tertiary institutions in Asia show that Asian students are committed to a low level, rote-biased (or surface) approach to learning. The students see university education, based on their extrinsic motivation, as a means to get a degree and to obtain a desirable job. They have a tendency to minimise their efforts but avoid failure. The strategy appropriate to meeting that intention is to limit the target to those essentials that may be reproduced through rote learning. Biggs (1989) shows that deep 
and achieving approaches to learning can be encouraged where the learning context encourages intrinsic motivation and attributions of ownership and self-efficacy, learner activity rather than passivity, and particular kinds of peer and teacher interaction.

Assessment methods have a strong effect on students' approaches to learning (Elton L. \& Laurillard D., 1979). Current educational research focuses on the relationships between different assessment methods and students' approaches to learning (Biggs, 1992; Biggs, 1996; Imrie, 1995; Tompkins \& McGraw, 1988).

This paper proposes the use of an Electronic Learning Contract (ELC) for assessing the outcomes of students' projects as well as the development and application of a Group Support System (GSS) for supporting the ELC. The ELC method has been tested in assessing the outcomes of students in the Department of Information Systems at the City University of Hong Kong. Quantitative data for comparing differences in students' approaches to learning have been obtained using Biggs' Study Process Questionnaire (SPQ) (Biggs, 1992). These data are used to analyse the impact of the new assessment method on students' approaches to learning.

\section{ELECTRONIC LEARNING CONTRACT}

Donald (1976) defines a learning contract as a document drawn up by a student and his instructor or advisor, which specifies what the student will learn, how this will be accomplished, within what period of time, and what the criteria of evaluation will be.

A learning contract is not just a document, it is the process that will encourage intrinsic motivation, active learning, and student-teacher interaction. Tompkins \& McGraw (1988) also emphasise the importance of the process, including the relationship between the student and teacher and the negotiation that occurs throughout the learning experience.

In this paper, an Electronic Learning Contract (ELC) is a continuously renegotiable working agreement between students and teachers which focuses on group decision making processes through electronic meetings in relation to the students' learning outcomes. A Group Support System (GSS) is used to assist the processes for discussing, negotiating, formulating, re-negotiating and revising the content of the electronic learning contract among students and lecturers.

A conceptual model of the ELC is shown in Figure 1. The tasks can be carried out in the following eight stages:

Stage 1: The lecturers design and draft the list of assessment criteria based on the project objectives, the available resources and the assessment guidelines and policies of the institution.

Stage 2: Students and lecturers discuss and negotiate, based on their perceptions of the assessment requirements, the content of the proposed assessment criteria using the GSS.

Stage 3: The lecturers then filter the generated opinions and prepare a vote for students and lecturers to select the assessment criteria for the project using the GSS. 


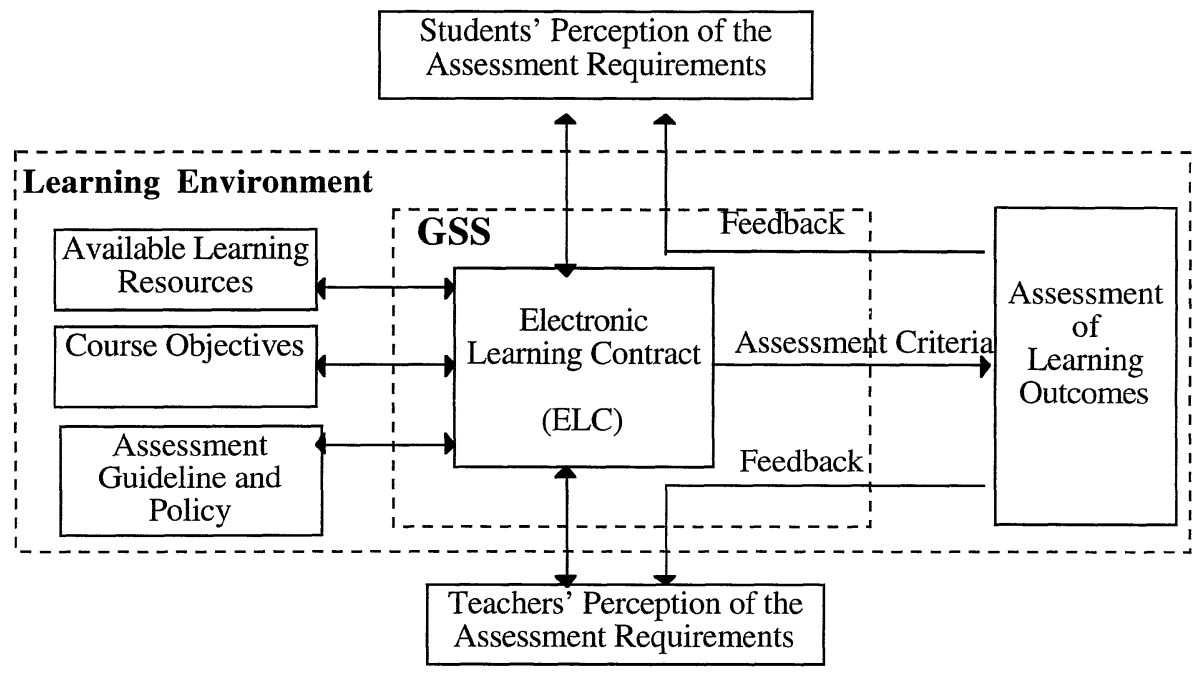

Figure 1 A Conceptual Model of the Electronic Learning Contract.

Stage 4: Students and lecturers select and rate the assessment criteria with respect to the objectives of the project.

Stage 5: The lecturers then process the result of the vote and formulate the final set of assessment criteria using the GSS. The final set of the assessment criteria will be announced and the students are allowed to enter their opinions on the results. Using the Delphi method, students and lecturers will then re-vote until most of the group is satisfied with the results, but the final decision is subject to the professional judgement of the lecturers.

Stage 6: Students and lecturers can express their opinion using the GSS on the agreed assessment criteria throughout the duration of the course. The list of agreed assessment criteria is subject to change if necessary. Students and lecturers can request revision of the assessment.

Stage 7: Lecturers will assess the students' learning outcomes according to the agreed assessment criteria throughout the course so that students get continuous feedback from the lecturers, and also students express their opinions on lecturers' comment on their performance.

Stage 8: Students also have the opportunity to self-assess their own performance and to peer-assess other students. Students can input their comment on their own performance and on that of other students.

\section{A GSS FOR ELECTRONIC LEARNING CONTRACT}

A GSS is an interactive computer-based system that facilitates the solving of unstructured problems by a group of decision makers. It supports more tasks than just decision making; it focuses on the processes used by working groups. It is an information technology based environment that supports group meetings, which may be distributed geographically and temporally (Turban, 1995). Group tasks include, but are 
not limited to, communication, planning, idea generation, problem solving, issue discussion, negotiation, conflict resolution and collaborative group activities.

A model of GSS is shown in Figure 2. These components are arranged to support the process of making a decision. The GSS includes a special decision model base for improvements of the decision making process, a database, an easy-to-use and flexible user interface, and a group facilitator procedure. The proposed GSS consists of all these components which will be discussed below.

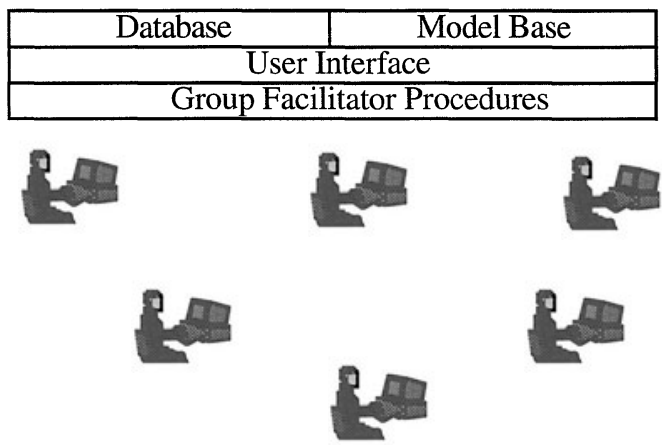

Figure 2 A Model of GSS (Turban, 1995).

The traditional negotiated learning contract is made between one lecturer and one student; it is quite easy to have the contract decided and agreed by both sides. It is more difficult to have a learning contract agreed by a number of students and lecturers within the proposed group facilitator procedure - the eight stages of ELC contracting processes previously mentioned. In order to smooth the contracting process and formulate a fair and non-threatening electronic learning contract, a fuzzy multi-criteria decision model (Chang \& Chen, 1994; Grabisch, 1995) can be used for assessment criteria selection.

Suppose there is a group of $n$ decision makers (D1, D2, .., Dn) who are responsible for evaluating the appropriateness of $m$ alternatives of assessment criteria (A1, A2, .., $\mathrm{A} m)$ under each of $k$ decision criteria $(\mathrm{C} 1, \mathrm{C} 2, \ldots, \mathrm{C} k)$ as well as the importance weight of the decision criteria. Let Sitj be the rating assigned to alternative A $i$ by decision maker $\mathrm{D} j$ under decision criterion $\mathrm{C} t$. Let $\mathrm{W} t j$ be the weight given to $\mathrm{C} t$ by decision maker $\mathrm{D} j$. The committee has to aggregate the rating Sitj of $n$ decision makers for each alternative $\mathrm{A} i$ versus each criterion $\mathrm{C} t$ to obtain the rating Sit. Each pooled Sit can further be weighted by weight $\mathrm{W} t$ according to the relative importance of the $k$ decision criteria. Then, the final score F $i$, fuzzy appropriateness index, of alternative A $i$ can be obtained by aggregating Sit and $\mathrm{W} t$. Finally, rank the final scores Fi, $(i=1,2, \ldots, m)$ to obtain the most appropriate alternative.

A database schema for the decision model of the proposed GSS is shown in Figure 3. The database schema is used to store necessary data for processing decision while the user interface is to allow the group to perform a joint function such as information entry, voting, or ranking alternatives through electronic meetings (Gray, Mandviwalla, Olfman \& Satzinger, 1993). To the user, the system is the interface. One example of the public screens of the proposed GSS is shown in Figure 4. 
PERSON(PID, Name);

LECTURER(PID, Appointment, Duty);

STUDENT(PID, Contribution, LearnAppr);

PROJECT(Proj-No, Total-Mark);

ASSIGN(PID, Proj-No);

A_CRITERIA(ANo, AssessCriteriaName);

D_CRITERIA(CNo, DecisionCriteriaName);

RÁTING(ANo, CNo, PID, Rating-Score);

WEIGHT(CNo, PID, CNo-Weight);

Figure 3 A database schema for the GSS.

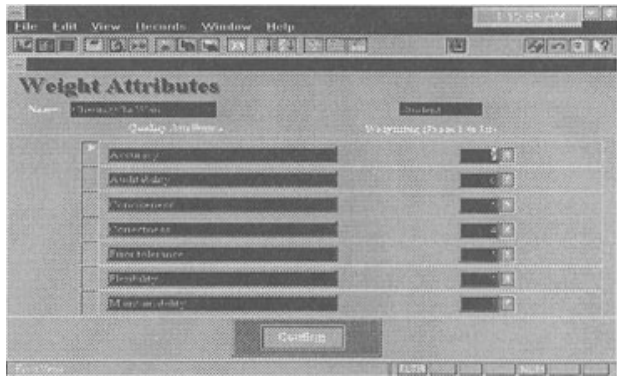

Figure 4 A screen for weighting the assessment criteria.

Finally, the goal of the GSS is to improve the productivity and effectiveness of electronic decision making meetings, either by speeding up the decision making process or by improving the quality of the resulting ELC. This is accomplished by providing support to the exchange of ideas, opinions, and preferences within the group.

\section{CONCLUSION}

In this paper, an electronic learning contract system is proposed for enhancing students' understanding of the assessment requirement and encouraging students to take the deep and achieving approaches to learning. This paper also suggests a fuzzy multi-criteria decision model for selecting assessment criteria. The concept of fuzzy sets is used in this paper because it can easily be used to describe the subjective selection of assessment criteria and the weightings of criteria. New methods of multi-criteria decision making need to be investigated to support the selection of assessment criteria and the weightings of criteria from decision makers of different importance.

Although the electronic learning contract in this paper is primarily designed to run on the university campus-wide computer network, it can be installed on Internet so that more stakeholders of the assessment policy in higher education, such as parents and future employers etc., can contribute their ideas in the assessment criteria decision processes. ELC can be applied for courses running on full-time, part-time or distance learning basis, at educational institutions or business organisations.

(The project work described in this paper was funded by the 1994 Strategic Research Grant of City University of Hong Kong and the 1994/95 Hong Kong Action Learning Project Grant).

\section{REFERENCES}

Biggs, J.B. (1989) Students' approach to learning in Anglo-Chinese schools. Educational Research Journal, 4, 8-17.

Biggs, J.B. (1991). Approaches to learning in secondary and tertiary students in Hong Kong: some comparative studies. Educational Research Journal, 6, 27-39.

Biggs, J.B. (1992). Why and how do Hong Kong students learn? (Using the Learning and Study Process Questionnaires). Faculty of Education, University of Hong Kong, Hong Kong.

Biggs, J.B. (1996). Assessing learning quality: reconciling institutional, staff and educational demands. Assessment \& Evaluation in Higher Education, 21(1), 5-15. 
Chang, P.L. \& Chen, Y.C. (1994). A fuzzy multi-criteria decision making method for technology transfer strategy selection in biotechnology. Fuzzy Sets and Systems, 63, 131-139.

Donald, J.G. (1976). Contracting for learning. Learning and Development, 7(5), 1-7.

Elton, L. \& Laurillard, D. (1979). Trends in students learning. Studies in Higher Education, 4, 87-102.

Grabisch, M. (1995). Fuzzy integral in multicriteria decision making. Fuzzy Sets and Systems, 69, 279-298.

Gray, P., Mandviwalla, M., Olfman, L. \& Satzinger J. (1993). The user interface in group support systems, in Group Support Systems (eds. L.Jessup \& J.S. Valacich), Macmillan, New York.

Imrie, B. W. (1995). Assessment for learning: quality and taxonomies. Assessment \& Evaluation in Higher Education, 20(2), 175-189.

Tompkins, C. \& McGraw, M.J. (1988). The negotiated learning contract, in Developing Student Autonomy in Learning (2nd Edition) (ed. D. Boud), Kogan Page, London.

Turban, E. (1995). Decision support and expert systems. Prentice Hall, London.

\section{BIOGRAPHIES}

Ron C.W. Kwok received the Certificate of Education in Physical Education from the Northcote College of Education (HK) in 1986, the B.Ed. degree in Physical Education from the University of Liverpool (UK) in 1990 and the M.Sc. degree in Information Systems from the University of Brighton (UK) in 1994. He has been a member of the Department of Information Systems of the City University of Hong Kong since 1995, where he currently is a MPhil student. His current research interests are in the areas of technology based learning, student's approaches to learning, assessment methods and group support system.

Jian Ma is an assistant professor in the Department of Information Systems at City University of Hong Kong. He received his Doctor of Engineering degree in Computer Science from Asian Institute of Technology. His research interests are in the areas of group decision support systems, object-oriented systems, database management, business process reengineering, and assessment of problem-based learning in engineering and business education. 